\title{
EVALUATING BASIC EDUCATION CURRICULUM FROM A GENDER PERSPECTIVE: ADDRESSING GENDER STEREOTYPES IN ELEMENTARY SCHOOL TEXTBOOKS
}

\author{
Eriada Çela ${ }^{1}$
}

\begin{abstract}
Addressing gender-equality issues in education can foster enormous change in children's lives. However, most textbooks in Albanian schools include gender stereotypes, which perpetuate gender inequality and unequal roles for men and women, both in public and private spheres. This research aims to identify and evaluate trends of gender stereotypes in textbooks, as well as the need for gender mainstreaming in basic education curriculum. The methodology is based on a desk review of textbooks from a gender perspective. The curriculum evaluation follows the context, input, process, and product (CIPP) model of evaluation, which mainly aims to assess the extent to which a certain education reform has generated positive change in schools.
\end{abstract}

UDC Classification: 305.3, DOI: http://dx.doi.org/10.12955/cbup.v4.812

Keywords: gender perspective, curriculum, evaluation, textbooks, stereotypes.

\section{Introduction}

Gender stereotypes are highly detrimental to academic and personal achievement of boys and girls alike, both in the short and long term. Stereotypes retain inequality and do not allow individual growth and discovery. When gender stereotypes are eliminated, most inequalities towards girls and women are avoided and odds for equal chances within school and life domains are increased. Moreover, when gender issues are officially eliminated within formal learning institutions, the change entailing the gender discourse is greatly improved. This research paper discusses the basic education curriculum in Albania, mainly the Civic Education textbooks, from a gender-equality perspective.

School is the basic educational institution that shapes all children who attend formal education, exposing them to general knowledge and concepts of citizenship behavior. When education fulfils its potential goal, all individuals have enhanced opportunities to change their lives, in terms of independence, freedom of thought, financial stability, and contribution to society. The curriculum plays a particular role in strengthening individuals, both in present decisions and future actions. As Walker (2006) stated, through education, girls are provided with "access to subject knowledge which will enable them to make future career choices, or simply enjoy this knowledge as an intrinsic good" (p. 175). However, education fails to fulfill this life-changing mission where the curriculum perpetuates gender inequality, both in the private and public sphere, and preserves hegemonic masculinity regimes, both nationally and globally (Arnot, 2002).

From this point of view, the curriculum plays a decisive role in the education of future citizens. Curriculum theorists, such as Goodson (1997), asserted that in carefully observing the content of the curriculum, one could find components that contributed in two directions simultaneously; namely, they had an empowering as well as a disempowering effect on boys and girls. Where the curriculum naturally transmits gender equitable education, all boys and girls attending school would be exposed to a fair standard of everyday behavior and teaching practices. Consequently, they would be more inclined to choose and internalize gender equitable models in their lives without trailing past gender stereotypes that limit their performances in all of life's domains.

\section{Methodology}

This study critically approached and evaluated basic education curriculum with a gender-equality perspective. The evaluation was partial, since it encapsulated specific elements of the curriculum, such as the syllabi and textbooks, without covering all the curriculum related elements. Specifically, the evaluation focused on one randomly selected textbook, Civic Education 5, and its syllabus prepared by the Curriculum Institute. The Civic Education textbook for grade 5 was published in 2007

\footnotetext{
${ }^{1}$ Eriada Çela, Aleksandër Xhuvani University, Elbasan, Albania, eriada.cela@gmail.com
} 
by the Education Development Institute, while the Civic Education textbook was authored by Kollcaku and Kullolli (2008).

This evaluation was external, since it was not performed by the same entity that designed or implemented the textbook through writing or publishing. It was informal because it was not undertaken by an organization that was officially responding to this process. It did not cover the curriculum in detail in regards to objectives and methodology, but rather analyzed the textbook from the gender perspective. The goal of this evaluation was to identify and review gender stereotyping in the text to identify potential improvements for the future. The logical model used in this curriculum evaluation was the context, input, process and product (CIPP) model that was created by Stufflebeam (1972). When used under the education framework, this model aims to identify whether a certain educational reform or initiative has successfully generated positive change in schools, universities, or training organizations.

\section{The Context}

The existing basic education curriculum in Albania has resulted from the last curriculum reform that started and continued from 1994 and was intensely implemented through 2003 to 2007, with total transformation of the previous curriculum, including past basic educational textbooks and their respective syllabi. This reform was aimed at mainstreaming the gender perspective into curricula from three different approaches: 1) reviewing and developing the pre-university and university curricula;2) issuing new textbooks with more than one alternative for teachers (alter-text); and 3) developing appropriate instructional materials (Albania, 2007). The same educational reform changed the basic duration for compulsory education from eight years (four grades primary and four grades lower secondary) to nine years (five primary and four lower secondary). As illustrated by curriculum researchers, "the curriculum changes aimed at improving the quality of basic education, adapting it to the social and economic development of our country, further exposing Albanian education to worldwide development, decentralizing the curriculum, as well as enriching the teaching and learning with new learning models" (Koci et al., 2011, p. 62). At that time, there was no Curriculum Framework that had been approved and thus, the two main national curriculum documents for the existing curriculum of grades 1-9 were the syllabus and the lesson plan.

\section{Input}

This evaluation acknowledged the list of sources that needed to be consulted and considered by the text writers and syllabus designers in designing and implementing the current basic education curriculum in Albania. In this context, input consisted of important national and international documents that had been ratified by the Albanian government, and included: Gender Equality Law, Family Code Amendments, and the respective issues that ensued. Additionally, equality issues and equal-chance opportunities were presented and principally solved according to the Education for All (EFA) project, which is now internationally approved (Ministry of Education and Science, 2009). Furthermore, Millennium Development Goals, under the framework of United Nations and European Partnership, was included to target the priorities for education and enrolment in the second cycle of studies for rural children, particularly girls.

Another crucial resource for the curriculum stakeholders to consider, before composing or approving the new textbooks and their respective syllabi, was the guideline for text writers regarding the gender perspective in basic education textbooks. Published by the Gender Development Alliance (Dhamo et al., 2008), this guideline for publishers and text writers emphasized multiple 'pitfalls' to be avoided when writing basic educational textbooks. The control list in this guideline included eradicating gender stereotypes in textbooks for the following that could pose problems for gender equity:

1. Visibility;

2. Stereotypes in terms of gender characteristics, relationships and professions;

3. Equal respect;

4. Gender sensitive vocabulary;

5. Illustrations; and

6. Authority. 
The overall goal was to reinforce the idea that gender stereotypes do not represent the vision of a democratic society with equal chance of development for boys and girls.

A further potential resource for the curriculum authorities was the list of competences for democratic and active citizenship. These competences implied that the designing of educational activities should suit the learning styles of all pupils, so that pupils can easily understand what is required of them and their cognitive style can be actively supported by their experience and previous knowledge about Democratic Citizenship Education and Human Rights Education.

\section{Process}

Aware of the important role of textbooks as the strongest educational instruments of information, education, and development, all stakeholders in education should carefully consider the integration of gender perspective as a tool for improving the quality of textbooks in education. Taking into account the full list of national, international, legal, and methodological resources available, the process of integrating the gender perspective into the basic education curriculum in Albania has remained incomplete. The extent to which all stakeholders were exposed to the list of potential resources, and beyond that accessed for this analysis, is unclear. However, the output appears to have overlooked gender equity in the basic education curriculum components.

\section{Product}

This evaluation identified a series of problems concerning the basic education curriculum, and this outcome further reinforces the need for mainstream integration of the gender perspective into textbooks and syllabi. The dominating problem was that the textbooks presented a clear-cut dichotomy of public and private, as well as polarized gender roles, which further reinforces gender stereotypes.

An example of polarized gender relationships was noticed in texts reflecting the domestic domain or household situation. Notably, the textbook writers had transmitted mixed messages in their textbooks. Thus, in cases where the text was focused on sharing the family responsibilities within family members, the content and the illustrations were explicitly more egalitarian. An ideally presented family picture included the mother, father, son, and daughter, together in idyllic harmony. However, in other units, where the primary goal was other than family responsibilities, the images expressed a different perspective. Most units containing household pictures mainly showed women in serving roles, for example, wearing an apron and serving meals to the other family members. One such picture of the domestic domain had all family members dining around the kitchen table and a speech 'bubble' from the son, intending to compliment the chef: "Compliments to mom".

\section{The Gender Perspective}

The curriculum analysis of gender perspective was drawn both quantitatively and qualitatively. This analysis grouped the Civic Education textbook findings by criteria specified by the Gender Development Alliance guideline, published by Dhamo et al. (2008). These guidelines are based on Sadker and Sadker (1994) criteria.

Hypothetically, all textbook writers and publishing houses have been provided with these guidelines and have signed a formal agreement accepting to abide by them in the textbooks they have produced and published. However, as this analysis points out, the Civic Education textbooks presented no gender balance for any of the criteria.

Visibility

In one textbook, most dialogues evolved around the characters of Arbër and Joni, and thus had boys as the main protagonists, and this could be viewed as openly positioning boys and girls in unequal terms of power within the classroom dynamics. In the same textbook, the circumstances that had female protagonists, Bora and Era, were less frequent or the female characters were mainly assigned secondary roles or supported male characters. In most cases, the boy, Arbër, was depicted as being curious, while the girl, Miri, was the goalkeeper. Arbër was the pupil who asked most of the questions in the dialogues and was the classroom senator, the team leader, and main scorer of the football team. Looking at such cases of protagonism in the Civic Education textbooks, one could notice that the characters in the dialogues do not show a balanced gender relationship in terms of visibility. 


\section{Stereotypes}

Being detrimental to boys and girls alike, stereotypes in the Civic Education textbooks appeared in terms of gender characteristics, relationships, and professions. The stereotypical characteristics were seen throughout the textbooks with girls mainly attributed to caring and submissive characteristics, while boys were portrayed as independent or goal-oriented. Also, relationships were depicted within unequal terms of power between boys and girls. For example, in the textbook, when the pupils choose to leave on an excursion, they followed Arbër's suggestions, and although Bora wished to proceed somewhere else, she was the one who compromised and simply abandoned her idea. Another detrimental gender stereotype observed in the analyzed textbook related to professions, which could affect the future professional choices of the girls.

Equal Respect

Identifying equal respect in the analysis revolved around evaluating all people's lives, diverse perspectives, and experiences, as equitable and worthy of coverage in the textbooks. However, traditional roles of females in caring or secondary positions dominated the scenarios in the textbooks. For example, the girl, Albana, helped the teacher with counting votes during the senator election, whereas the candidates were, Arbër, Ilir, and Bora, and the elected senator was the boy, Arbër.

Gender Sensitive Vocabulary

Overall, the analyzed syllabi tended to be gender neutral since the pupils were addressed as homogenous groups or categories. In addition, when objectives were outlined, children and pupils were addressed as a plural noun, which in Albanian is presented as belonging to the masculine gender.

\section{Illustrations}

Throughout the wide list of domains in which people are presented in the textbook, women were mainly seen within the household and surrounded by children. Men, however, were wearing a suit and tie, even in pictures portraying the domestic environment. Where women were presented in the work environment, they were mostly teachers. On the contrary, men were presented in a wide range of professions, from engineers to doctors and economists. The frequency of men and women appearing in such stereotypical professions or relationships could only perpetuate gender stereotypes.

Authority

Men and boys were explicitly attributed more authority than the women and girls in the textbooks. When Era asked her mother on a business plan, she was informed by her mother to go to her father, as he is the one who knows everything about business. In other cases, where children were presented as curious about issues such as production, transportation, or local community voting, the father was the authoritative figure to whom children addressed and directed questions. Boys were frequently depicted as being more curious, whereas girls were shown as submissive and supportive, and thus, there was a gender bias in terms of authority, both in household and working domains.

\section{Conclusion}

The basic education curriculum in Albania has been subject to several changes over the past decades, many of which have been aimed at integrating existing knowledge and information into basic educational textbooks and programs. This paper utilizes the curriculum evaluation model for context, input, process, and product (CIPP) to evaluate the basic educational curriculum from a genderequality perspective. Aiming to identify and openly discuss the gender stereotypes in elementary school textbooks, this research resonates with previous research and further reinforces the need for serious consideration of the gender equity mechanisms that should be present in the basic education curriculum.

Being the cornerstone of the formal educational system, the school is responsible for shaping individuals by exposing them to basic concepts and knowledge. The basic education curriculum, textbooks in particular, comprises the gist of education, to provide boys and girls with the knowledge, skills, and behavior to succeed in society. Where education fails to achieve its life-changing goal is in the curriculum that perpetuates gender inequality, both in public and private spheres. Therefore, integrating the gender perspective in education is an utmost necessity in helping boys and girls explore and achieve their maximum potential, without being restricted by gender stereotypes. 
In this respect, the existing education situation in Albania possibly faces a series of difficulties in proceeding to the ideal situation. In endeavoring to reform the complete education system, the most recent educational reform has failed to wholly integrate the gender perspective into the basic education curriculum, the Civic Education textbooks, or the respective syllabi. The eradication of gender stereotypes from education components still faces several conceptual and methodological problems. Curriculum specialists have also affirmed, "there are no differentiated learning elements in the syllabi, while most of the textbooks are difficult and overloaded with concepts. They lack the right guidance to develop critical and creative thinking, group work skill and project work" (Hamza \& Spahiu, 2011, p. 7). The textbook components relating to skills and practices that were discussed in this article are fundamental to empowering girls and women. Such gender-equality components offer children and adults the power to disentangle and uproot gender-based stereotypes; hence their absence in the textbooks is contrary to gender-equitable education.

\section{References}

Albania (2007). Ministry of Labour, Social Affairs and Equal Opportunities, National Strategy on Gender Equality and Domestic Violence 2007-2010. Retrieved January 15, 2013 from: http://www.mpcs.gov.al/dpshb/images/stories/dpshb/2.1._National_Strategy_for_Gender_Equality_and_Domestic_Violence .pdf

Arnot, M. (2002). Reproducing gender: Essays on educational theory and feminist politics. London: Routledge Falmer. Civic Education Syllabus (2007) Grade 5, Academic Year 2008-2009. Tirana: Education Development Institute.

Dhamo, M. et al (2008) Gender perspective in school textbooks: guidelines for the school textbook publishing house. Tirana. Goodson, I. (1997). The changing curriculum: Studies of social construction. New York: Peter Lang.

Hamza, M., \& Spahiu, Y. (2011). "Reviewing the basic education curricula", in Comparative analysis of the current basic education curricula and the basic education curricula of other countries. Tirana: Pedagogic Journal

Koci et al. (2011). "The current curriculum analysis, classes 1-9" in Comparative analysis of the current basic education curricula and the basic education curricula of other countries. Tirana: Pedagogic Journal

Kollcaku, M. \& Kullolli, B. (2008) Civic Education V, Tirana: Filara-2002 Publishing House.

Ministry of Education and Science. (2009) The National Strategy of pre-university Education. Tirana

Sadker, D., Sadker, M. (1994). Failing at Fairness: How Our Schools Cheat Girls. Toronto, ON: Simon \& Schuster Inc.: 284. Stufflebeam, D. L. (1972). The relevance of the CIPP evaluation model for educational accountability. SRIS Quarterly, 5(1)

Walker, M. (2006). Towards a Capability-based Theory of Social Justice for Education Policy-making. Journal of Education Policy, 21(2), 163-185. 